\title{
A Knowledge-Based Digital Lifecycle-Oriented Asset Optimisation
}

\author{
Theresa Passath, Cornelia Huber, Linus Kohl, Hubert Biedermann*, Fazel Ansari
}

\begin{abstract}
The digitalisation of the value chain promotes sophisticated virtual product models known as digital twins (DT) in all asset-life-cycle (ALC) phases. These models. however, fail on representing the entire phases of asset-life-cycle (ALC), and do not allow continuous life-cycle-costing (LCC). Hence, energy efficiency and resource optimisation across the entire circular value chain is neglected. This paper demonstrates how ALC optimisation can be achieved by incorporating all product life-cycle phases through the use of a RAMS²-toolbox and the generation of a knowledge-based DT. The benefits of the developed model are demonstrated in a simulation, considering RAMS² (Reliability, Availability, Maintainability, Safety and Sustainability) and the linking of heterogeneous data, with the help of a dynamic Bayesian network (DBN).
\end{abstract}

Keywords: criticality analysis; digital twin; dynamic Bayesian network; knowledge-based maintenance; RAMS²

\section{INTRODUCTION}

Today digitisation and Industry 4.0 significantly influence on management and operation of industrial companies. Over the past years, a multitude of enabling technologies for a digital transformation has been introduced to the industrial context, like Digital Twin (DT), which also raises new challenges and opportunities for asset management [1]. An efficient use of the capital-intensive resource of asset is becoming increasingly important, especially in the view of rising automation and the associated substitution of the production factor labour (human) by the production factor asset (machine) [2-4]. In addition, the digital transformation is bringing major changes to the industry through rising data volumes from networked production systems (e.g. industrial internet of things and cyper-physical production systems) and the ability to analyse them. These could be opportunities for qualitative growth and shape the idea of sustainability within a company, especially if resource consumption is reduced from an overall economic perspective and thus environmental relief is achieved through e.g. $\mathrm{CO}_{2}$ reduction [3]. The aim of anchoring the concept of sustainability in the asset management is to minimise the cost incurred over the life cycle of an asset - life-cycle-costs (LCC). For functional asset management, it is vital to consider the entire asset-lifecycle (ALC), starting with the planning-/development- and ending with the disposal-phase. This holistic view enables a reduction of asset LCC by aligning all processes and decisions [4]. In the best case, a cooperation and continuous data exchange between the asset manufacturer and the asset operator exists. This is the basis for a transparent, dynamic adjustment of maintenance strategies, optimal resource utilisation and improved LCC with end-to-end knowledge protection using data linked across all life-cycle phases.

This paper presents the WissensFab model and addresses the concept and related steps for developing a lifecycleoriented asset optimisation through a knowledge-based DT. This goal is achieved by a dynamic asset evaluation, considering RAMS $^{2}$ (Reliability, Availability, Maintainability, Safety and Sustainability) and the linking of heterogeneous data from the considered assets and their life cycles with the help of a dynamic Bayesian network (DBN) to develop a DT. Furthermore, the model is validated by means of a simulation in laboratory character with real machine data. In the run-up to the selection of the machine data, a criticality analysis of an asset park, which is part of the RAMS ${ }^{2}$ toolbox was carried out by an asset operator. The most critical assets were analysed in detail and the input data (asset index/KPIs) were transferred to DT. The results of the simulation from the WissensFab model are discussed in the last section.

The paper is structured as follows: In chapter 2, a stateof-the-art analysis of the current literature in the field of DT, DBN and asset valuation is done. In chapter 3, the WissensFab model is presented in detail and its results are finally discussed in chapter 4 .

\section{THEORETHICAL BACKGROUND}

This section looks at the theoretical background around the terms DT, DBN, asset management especially at criticality analysis and LCC.

\subsection{The Digital Twin in Life Cycle Environment}

Digitisation in the value chain is one of the main driving forces in the use of sophisticated virtual product models, called DT at all stages of the ALC, according to "Gartner's Top 10 Strategic Technology Trends for 2017". DT as initially defined by NASA is "an integrated multi-physics, multi-scale, probabilistic simulation of a system, that uses the best available physical models, sensor updated, feet history, etc. to mirror the life of its flying twin" [5]. Over time, this simulation-based understanding evolved. However, it is ambiguously introduced in the literature. The German Industry 4.0 platform defines a DT as the "digital representation of a $[\ldots]$ product $[. .$.$] within a single life cycle$ or across different life cycles using models, information, and data" [6]. This means that virtual models are created from physical objects in a digital way and linked to simulate their behaviour in real environments using data streams $[8,9]$.

According to Grives [7], DT is composed of three components, the i) physical entities in the real world, ii) the virtual models in the cyber world and iii) the connected data 
linking the two worlds. Fig. 1 expands these components to six dimensions, based on Uhlenkamp et al. [8-10]. These identified dimensions are derived from frequent occurring application areas.

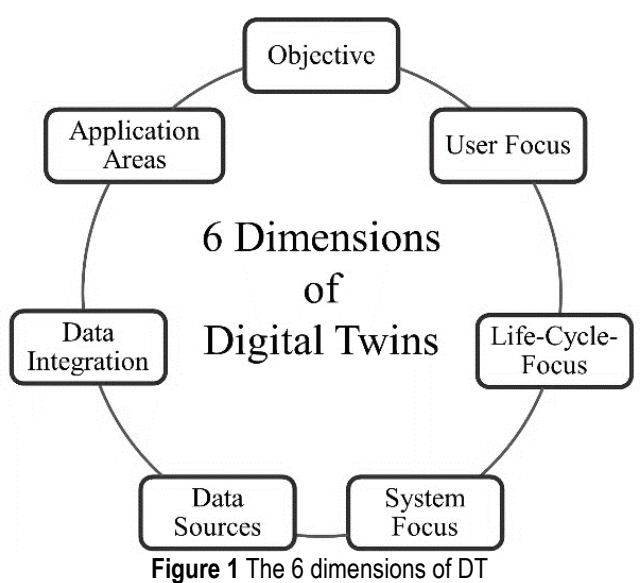

The application areas of a DT range from the use in i) product design [13] specifically in simulation [14], to ii) production, iii) maintenance [9] and iv) networking and communication across asset manufactures and operators [15]. The DT used in simulating production applications often includes data of the asset operators, material, equipment, tools, environment, behaviour, rules and dynamic models, derived from expert knowledge, which can be optimised by the DT [14]. A core aspect of a DT are digital and seamless information flows, which are an essential aspect [16] to efficiently and effectively run through the ALC-phases. Furthermore, the vertical data integration across the ALC-phases, as well as horizontal integration are necessary $[17,18]$.

For the design phase, the interaction between the physical and the expected virtual world is represented in the DT [13]. The virtual model can reflect both the designer's and the customer's expectations, as well as the practical constraints in the physical world [19]. Especially in predictive maintenance [9], the collection of static and dynamic machine information (e.g., master data and motion data) plays a crucial role, however, the collection turns out to be particularly complex. This leads to wrong results in proven analysis models, because of the missing possibility to combine static and dynamic machine data. This underlines the need to combine up-to-date data and information with the content of technical documents in dedicated analysis models [20]. The combination of these different data sources becomes even more important when a DT is used across the ALC phases. In this case, data exchange between asset manufacturer and operator is a necessity [15].

\subsection{Knowledge Representation Using Dynamic Bayesian Networks}

To create a DT representing the ALC, appropriate methods for linking those heterogeneous data and information sources, including a temporal dimension, are needed. In particular, to link newly extracted knowledge with prior knowledge and documented experience to achieve a higher degree of data integration, this is essential [9]. Knowledge-based methods are an essential part of artificial intelligence (AI) research, which has been increasingly integrated into production management systems in recent years, especially in knowledge-based maintenance [21, 22]. In this context, particularly in maintenance, it is important to combine various objectives from industrial companies' technical, functional and economical areas [23]. Maintenance measures that are carried out at the right time are key in ensuring the asset's availability, product quality, and process efficiency in modern manufacturing systems [24, 25]. However, it is increasingly important to add a cost dimension to these classic targets [26].

Bayesian networks $(\mathrm{BN})$ are graphical methods for knowledge representation. Their advantages to other AI methods are the possibility of graphical visualisation, easier traceability of cause-effect chains, as well as the possibility of using knowledge-based inferences [27-29]. Important steps towards the use of BN in ALC-assessment have already been set by Dienst [27], as well as their use in knowledgebased maintenance [28]. Dynamic BN (DBN) can be created from an object-oriented BN (OOBN) by selecting a learning algorithm and a DBN by adding a temporal component [27]. The use of DBN for creating a DT [28] in maintenance [29] shows the great potential of this method. The possibility of semantic linkage and the possibility of generating knowledge out of the represented data are particularly noteworthy. $\mathrm{BN}$ is also increasingly used in product development [30] and in the design of sustainable product lines under consideration of the multi-life cycle [31].

\subsection{Asset Valuation under Consideration of Life Cycle Costing}

Numerous holistic approaches in asset management contribute to minimising LCC and increasing resource efficiency in asset management. One of the best-known approaches is the Total Productive Maintenance (TPM) concept. The overall goal of TPM is to maximise the asset effectiveness with respect to the entire life cycle [32]. Furthermore, the Lean Smart Maintenance (LSM) philosophy focuses on a value-added-oriented design of maintenance management. LSM is taking into consideration the latest technological advancement (aka Industry 4.0), with the goal of a resource-efficient asset management over the entire ALC (planning, use, retirement) [33]. By optimising LCC and downtime costs, LSM follows a dual approach to increase efficiency and effectiveness of maintenance [34], which are reinforced by the standards and norms ISO 55000 and DIN EN 16646. Regarding the area of sustainable development of corporate management, there are standards and norms such as ISO 14001 or EMAS, which are increasingly used in companies to consider or comply with environmental aspects.

Life cycle assessment is described by international standards ISO 14040 and ISO 14044. Furthermore, there are also legally required benchmarks, for example the European 
Parliament Regulation (2018/842) which sets annual climate targets. These factors influence the company's value system, their activities to elaborate, design and steer a sustainable economic, environmental and social development [3]. Another methodology that has become established is RAMS (Reliability, Availability, Maintainability, Safety), which can be used to prevent errors already in the planning phase of projects. RAMS management ensures that systems are defined, risk analyses are carried out, hazards are identified and detailed checks and safety certificates are produced. To perform a detailed risk analysis, the first step is to identify critical assets to narrow the scope of consideration. There are some methods used to identify critical assets, such as FMECA (Failure Mode and Effects and Criticality Analysis), ABC classification [35], risk analysis [36], Analytical Hierarchy Process [35], fuzzy analysis, CEIM (cost-effective maintenance measure) [37], and Weibull analysis [38]. Another example of an already existent methodology is the criticality assessment adapted from Kinz et al. [39], which consists of the steps of asset selection, criteria assessment, identification of critical assets and detailed analyses for cost and risk reduction [40, 41]. Through the implementation of Life-Cycle-Assessment (LCA), these detailed analyses enable the consideration of environmental goals and contribute significantly to a holistic decision-making process. An experience-based assessment methodology causes human errors and long decision paths due to uncertainty of the people involved. The more important it is to reduce the human influence and to carry out the assessment automatically, based on quantitative criteria [42].

The methodologies currently used in literature usually only shed light on maintenance per se and its impact on the asset availability. Factors such as data quality, production, company- and sustainability-related influencing factors are disregarded, as shown in the work of Adams et al. [43], Bharadwaj [44] and Crespo Marquez et al. [35]. Usually, two criteria (extent of damage and probability of failure) are used for the evaluation [45]. A holistic view of the organisation and all influencing factors (costs, quality, sustainability, time and flexibility) on maintenance by integrating them in the asset evaluation is currently not existent. The need for such an easy-to-use, quantitative, dynamic, data-based assessment methodology has been identified in the literature, but does not yet exist [46].

In summary, it is noted that currently:

- The experience-based assessment is in the foreground in the literature and no standardised procedure model for criticality assessment based on the existing data quality and complexity of the company exists.

- Furthermore, the combination of criticality assessment with RAMS ${ }^{2}$ (RAMS \& Sustainability) methods with a DT using DBN, is completely new.

\section{WISSENSFAB MODEL}

The WissensFab model fills the gap by leveraging the benefits of DBN [47], specifically in knowledge-based maintenance, to preserve and use existing expertise and learn from experience and past events to generate new knowledge [2]. While most data-driven maintenance strategies aim at increasing the availability, the WissensFab model uses DBN, extends this classic approach by a LCC dimension [48]. Due to the ability to represent knowledge from heterogeneous data sources, DBN can also be used for recommended actions. This has been successfully applied in healthcare [49] and especially in predictive maintenance of industrial equipment and production quality management [50]. DBNs are particularly suitable for the extraction of expert knowledge from heterogeneous data sources. The WissensFab model takes advantage of the semantic linkage of heterogeneous data sources and the temporal properties of DBN to introduce another sustainable dimension into the DT in the course of life cycle management.

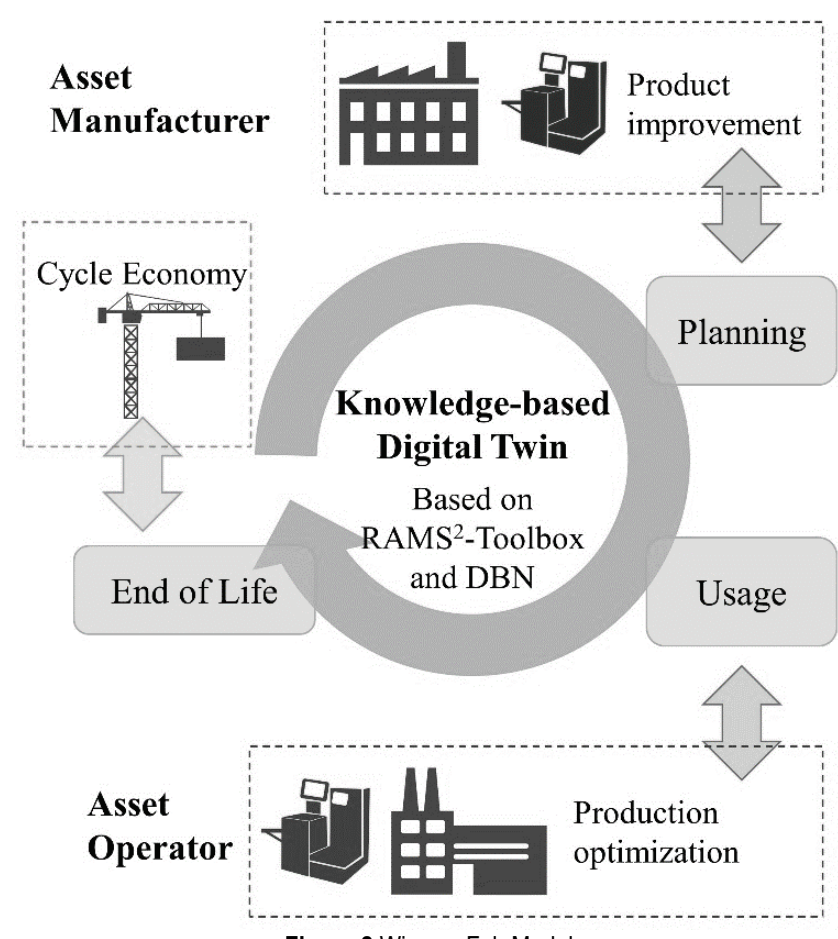

Figure 2 WissensFab Model

The overall objectives of the WissensFab model are to build a lifecycle-oriented asset optimisation based on the results of the criticality assessment through a knowledgebased DT (Fig. 2).

The model contains a set of instruments tailored to the respective asset manufacturer and operator and contributes process and product optimisation from an economic and ecological point of view in the various life cycle phases of an asset. Knowledge is presented transparently through standardised processes. This leads to a reduction in downtime costs, an increase in availability, improved product quality through a reduction of rejects, savings in material and energy resources, a reduction of reworking times and a reduction of LCC through improved product development. By using a knowledge-based DT, these savings potentials can be made visible at an early stage and targeted measures can be taken. The WissensFab model comprises three components:

- RAMS $^{2}$-Toolbox 
- Innovative Knowledgebase with DBN

- Digital Twin.

All three components are created and tested in simulation, using data from industrial use cases. The individual components are presented in the following sections and the results are discussed at the end.

\subsection{RAMS2-Toolbox}

For a sustainable asset evaluation, the RAMS model is extended by the aspect "Sustainability" (RAMS ${ }^{2}$ ) in order to include environmental considerations in the criticality evaluation. RAMS is defined in CENELEC-Norm EN50126 [51] like:

- Reliability Engineering

- Availability Engineering

- Maintainability Engineering

- Safety Engineering.

It focuses on the use of targeted, product-specific hazard, reliability, maintainability, safety and sustainability analysis (Fig. 3). Life cycle thinking is used to ensure minimisation of potential hazards of humans and the environment and maximisation of reliability and safety of products and processes.

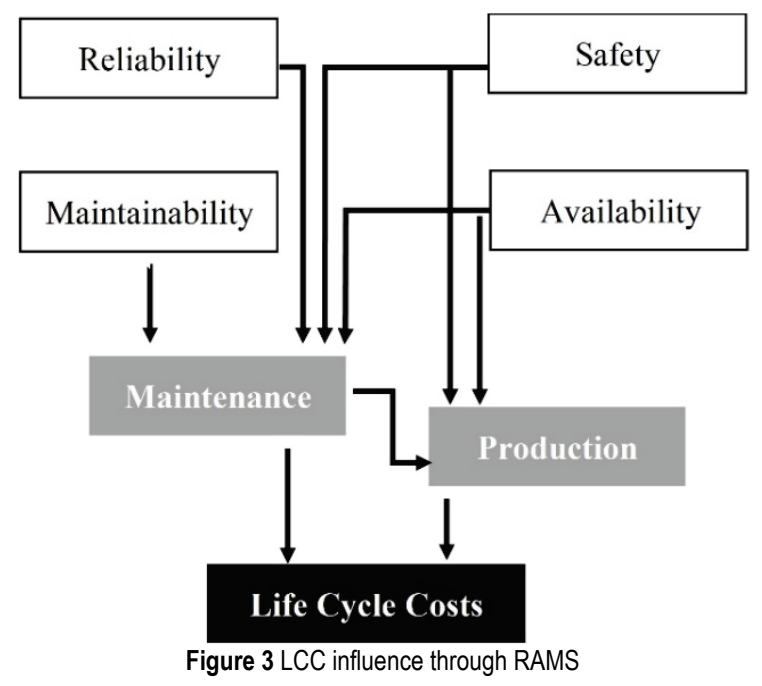

$\mathrm{RAMS}^{2}$ enables a resource and energy evaluation in the value chain with simultaneous consideration of the LCC. This novel approach enables a fusion of traditional metrics with sustainable aspects, which increases the benefit of the application for industry partners and thus creates a companywide increase of knowledge. This leads to a transformation towards a climate-friendly, resource-efficient factory.

The RAMS ${ }^{2}$ toolbox (Fig. 4) contains various instruments that can be selected individually for each company. In the course of the requirement analysis, the ALC is evaluated in terms of data quality and risk tolerance by the cooperation of the asset manufacturer and the asset operator, applying the RAMS ${ }^{2}$ toolbox. The performed data quality and criticality analysis in combination with a consideration of $\mathrm{RAMS}^{2}$ over the entire ALC represents an innovation beyond the current state of the art.

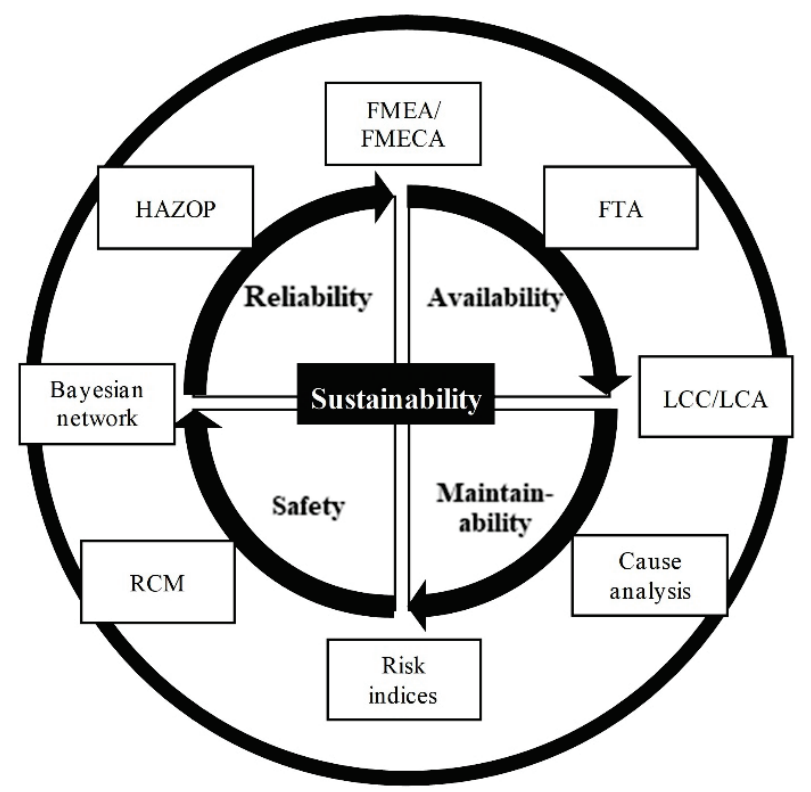

Figure 4 Excerpt from the RAMS² Toolbox

The RAMS ${ }^{2}$ methods are used for criticality and weak point analyses, based on the existing processes and data by selected use-cases. This can ensure a holistic view of assets through technical, economic and sustainability criteria. The output of the criticality assessment (asset index / RPI) serves as input for the DBN of the DT. Furthermore, in turn, the output of the DT is fed back through iteration loops as additional/extended input for further criticality assessments. This makes it possible to derive control mechanisms for decision-making and check which effects decisions have on individual KPIs.

\subsection{Identification of Most Critical Assets}

The criticality assessment adapted from Kinz et al. [41] is applied in combination with the HAZOP [1] approach to identify the most critical assets. This criticality analysis method includes four steps $[49,1]$ :

1) Asset selection \& Criteria Selection

2) Asset evaluation

3) Creation of an asset priority portfolio

4) Detailed asset analyses.

In the first step, it is important to set limits for the selection of assets for the asset evaluation based on the success factors of the company. It does not make sense to evaluate all assets in the course of the asset evaluation. The larger the asset park, the more important it is to make a preliminary selection on the basis of defined characteristics. These characteristics have direct impact on the success of the production, and in broader sense, on the company. Furthermore, in the first step of the criticality analysis, the preselected assets are evaluated based on the defined criteria, which were derived from the company's success factors. It is 
important to use criteria from different categories like cost, time, quality, flexibility, sustainability and safety, which are reflected in the different categories of the RAMS ${ }^{2}$. They can include the common time and cost-related criteria, such as asset availability, downtime or maintenance costs, as well as quality-related criteria such as scrap or supplier quality. For sustainability criteria, it is useful to consider the three key areas ecological, economic and social issues, such as environmental pollution, pollutant emissions, the degree of risk to operators, the location of the asset or the criterion of health risk [14]. Tab. 1 shows some examples for criteria for the asset analysis with the assignment to the RAMS ${ }^{2}$ categories.

Table 1 Examples for asset criteria with RAMS²

\begin{tabular}{|c|c|}
\hline RAMS $^{2}$ & $\begin{array}{c}\text { Criteria/KPIs } \\
\text { R }\end{array}$ \\
\hline $\mathrm{A}$ & $\begin{array}{c}\text { Product quality, material range, delivery reliability, } \\
\text { maintenance requirement }\end{array}$ \\
\hline $\mathrm{M}$ & Availability, performance level, scrap rate \\
\hline $\mathrm{S}$ & $\begin{array}{c}\text { Overdue maintenance, MTTR, prevention rate, } \\
\text { qualification level }\end{array}$ \\
\hline $\mathrm{S}$ & Lost time injury rate, occupational accidents \\
\hline
\end{tabular}

The asset evaluation (step 2) is an integral part of the implementation phase of the HAZOP approach. In this step, the preselected assets are rated based on the predefined criteria. In the best case, this step is done automatically with a software tool. Therefore, only quantitative criteria can be used. If automated assessment is desired, there must be uniform data availability at asset level and uniform data quality. The result of the asset evaluation is the asset index for each of the assets valued. The asset classification is depended on the asset index. The higher the asset index, the more critical an asset is [34].

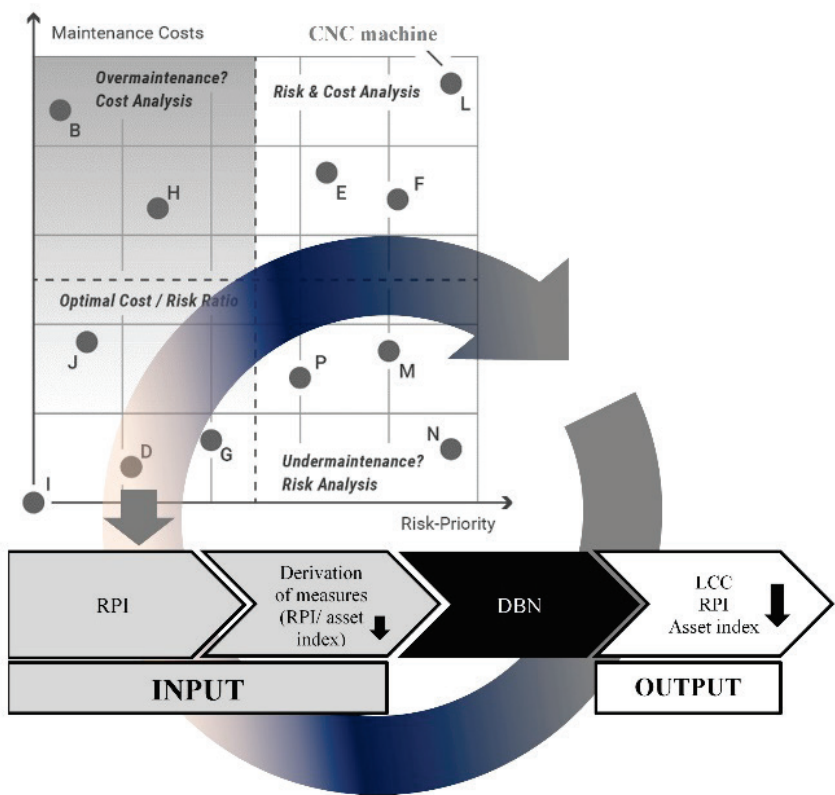

Figure 5 Asset priority portfolio as input for DBN to reduce LCC

The results are visualised in an asset priority portfolio (step three), in which the criticality or in more detail the different dimensions of the criteria $\left(\mathrm{RAMS}^{2}\right)$ are compared to the direct maintenance costs [49]. Fig. 5 shows an asset priority portfolio, where the $\mathrm{CNC}$ machine was identified as one of the most critical assets.

The fourth step is to examine the assets identified as most critical in detail and try to adjust the maintenance strategy by considering the defined measures for risk and cost reduction. Therefore, each criterion is analysed in detail and the consequences of such high-risk level are considered. Potential as well as already occurred risks of the respective critical asset (CNC machine in this case) are assessed at component level according to the probability of occurrence, the extent of damage and the potential consequences (quality, safety, time, ...), the probability of detection as well as the effort to be expended for risk reduction with the maintenance risk prioritisation tool. The result of the evaluation is the risk prioritisation index (RPI), which gives a rating of how critical the respective error is. The higher the calculated RPI, the more important it is for this risk to implement the intended risk reduction measure as quickly as possible. The measures for risk reduction can be derived at component level.

The detailed cost analysis includes the division of the costs in their cost types to identify the largest cost drivers. Generally, for both analyses-types (risk- and cost-analyses), measures are derived and the saving potential is considered in the reduction of the asset index/RPI. This regular automated system evaluation as the basis for detailed analyses supplies input data (RPI/KPIs) for the DT.

\subsection{Innovative Knowledge-Base with DBN and Digital Twin Demonstrator}

A DT for the simulation of the industrial use cases is created from the heterogeneous data sources spanning the ALC with the help of DBN. The classical simulation approach will be extended by the dynamic aspect of a BN, as well as by a semantic linkage, to map the temporal component in the process and to extract relevant KPIs. The example discussed in this paper represents the simulation of a CNC machine and its LCC over the ALC. The CNC machine has been identified as the most critical asset in the analysed asset park by the criticality assessment. In the example shown in Fig. 6, sensor data from the asset operations (motor rotation, electric current, oil pressure, oil temperature, and main spindle speed) are linked with data from the operation (output power, feed and operating hours) and asset components (motor and cutting tool). An asset failure consists of the combined inputs from sensor data, operating data and asset data. In the simulation use-case for example, the cutting tool, combined with the feed, the electric current and the motor rotation represent combined an asset failure. The failures are derived from the criticality assessment (detailed CNC risk analysis). The modelling of these failures is done with experts from the asset operator.

Two types of KPIs can be derived from these failures namely from the:

- Operational phase

- Quality 
- Reliability

- Availability

- MTTR

- $\quad$ Lost time injury rate (LTIR)

- Resource consumption (RC)

- Design phase

- Motor power

- Intended use

- Efficiency.

The KPIs from the operational phase also reflect the $\mathrm{RAMS}^{2}$. The results of the KPIs of the operational phase can be used to optimise the ongoing asset usage by using the identified measures for risk reduction. The results of the KPIs of the design phase can be used in the next product iteration. Once the KPIs of the operational phase have been optimised, this will have an impact on the sensor and asset data of the next time period. Based on the changed parameters, the failure frequency occurrence and the potential extent of damage also change in the following time period. This leads to adjusted measures in the risk assessment. In the case of different potential measures to optimise the KPIs of the operational phase, the DT also helps to select the most efficient measure, as it simulates the effects of the measures and therefore provides a data-based decision-making tool. The knowledge-based DT therefore represents a continuously self-improving system.

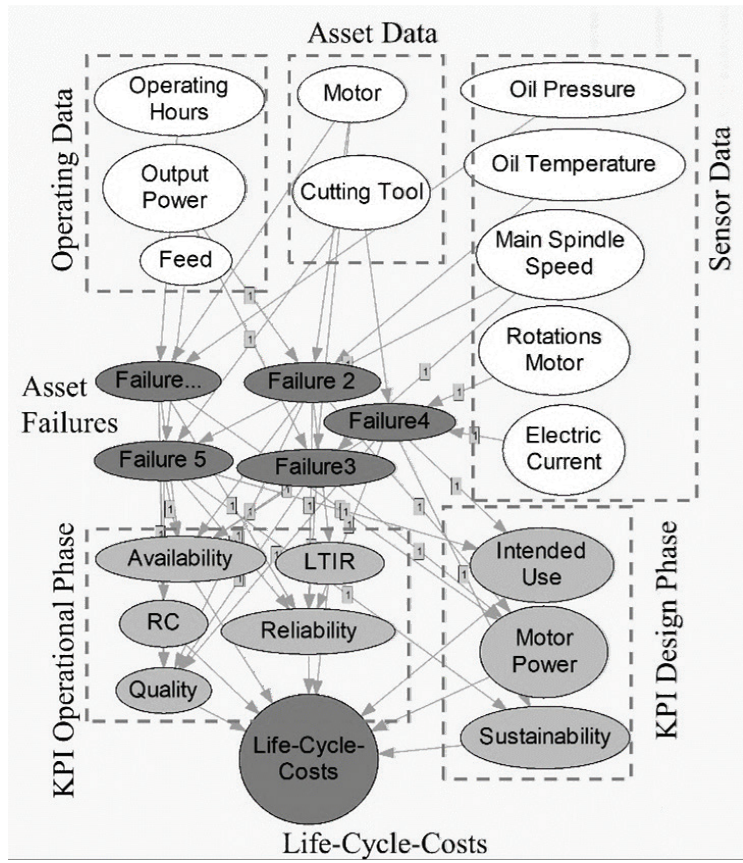

Figure 6 DBN simulation of a CNC machine over the product life cycle

This happens in analogy by the improvement of the KPIs of the design phase. These do not automatically have an effect on the next period of the machine in operation, but they significantly improve the machine data in the next product generation. Those KPIs can be used in the next product iteration, e.g. to adapt the asset to the real usage profiles, the results of the sustainability analysis or the required engine power. In combination the KPIs from the operational and the design phase are used together to calculate the LCC. Their continuous adjustment leads also to a decreasing asset index. By optimising the operational KPIs in each time period, as well as the KPIs from the design phase the LCC of the asset can be reduced continuously by optimising the maintenance strategy based on the results of the simulation. This innovative approach enables knowledge representation, the derivation of KPIs for each ALC-phase, the derivation of product design recommendations and the calculation of lifecycle costs in a dynamic model. For the data exchange required in this case, it is necessary that both the asset operator and the asset manufacturer can access the DT at all times. If this is the case, the model presented here makes it possible to dynamically adjust various KPIs and furthermore adapt the maintenance strategy over the product life cycle and product iterations.

\section{DISCUSSION AND OUTLOOK}

The result of the simulated knowledge-based DT using DBN serves to prove the functionality of the combined use of the RAMS ${ }^{2}$ toolbox and the DBN, which enable a lifecycle-oriented asset optimisation by including heterogeneous data sources. With the help of the demonstrator, asset manufacturers and operators will be able to achieve a use-case dependent reduction in maintenance costs, an increase in asset availability, a reduction in LCC by means of improved product development, a continuous safeguarding of knowledge, as well as a simultaneous reduction in $\mathrm{CO}_{2}$ emissions and an optimisation of decisionmaking with increasing transparency.

LCC has a great advantage for both asset manufacturers and operators. By knowing the LCC, the asset manufacturer can design the assets in a more targeted way to have lower operating costs during the utilisation phase. The DT results also enable the asset manufacturer to systematically improve the next generation of the machine, considering the asset operators' needs and production conditions (see Fig. 1 planning phase).

The advantages for the asset manufacturer regarding the optimisation of machines in the planning phase for future applications is evident. This enables the asset manufacturer to become even more familiar with his customers and to react to trends and changes in the markets of the customer group. The difficulty here for the asset manufacturer is not to use the data obtained to optimise a manufacturer's production settings for a product but to convert this data into a product development strategy from which all customer groups benefit. The asset manufacturer can use the reduced LCC as an argumentation basis towards the customer and build up economic service concepts or new business models.

The DT provides an opportunity for a continuous improvement of the assets and dynamic adaption of the maintenance strategy in the operation phase for the asset operator (see Fig. 1). After each optimisation of the KPIs during the operation phase, the optimised parameters of the asset operation, consisting of machine, operational and sensor data, are available in the following time step. In the 
following validation cycle these parameters serve as input for the next improvement of the operational KPIs. This continuous improvement of the asset operators KPIs of the operational phase in combination with the periodic improvement of the asset manufacturers design phase KPIs leads to a continuous reduction of the LCC. The asset operator can use the optimised LCC to select and procure assets and plan the total costs at an early stage. LCC can be used to derive maintenance concepts and thus optimise maintenance.

The knowledge-based DT clearly shows the advantages of combining criticality analysis based on RAMS ${ }^{2}$ with a DBN to continuously reduce the LCC and reduce the asset index/risk potential of the critical assets. The presented approach has the great advantage of representing a generic method applied to almost any domain. The domain-specific adaptation takes place using the expert knowledge of the employees involved in the design of the DT. However, this can also be seen as a limitation, as the approach can only be automated to a limited extent. It still requires human expertise to apply the criticality analyses and RAMS ${ }^{2}$ toolbox and to model the DBN.

In future research, the end-of-life phase needs to be studied in more detail. For the asset manufacturer in particular, this represents a very large untapped potential with recycling and after-use concepts. However, the asset operator can also make further use of this phase, e.g. by building up synergies with downstream users.

\section{Notice}

The paper will be presented at MOTSP $2021-12^{\text {th }}$ International Conference Management of Technology - Step to Sustainable Production, which will take place in Poreč/Porenzo, Istria (Croatia), on September 8-10, 2021. The paper will not be published anywhere else.

\section{REFERENCES}

[1] Passath, T., Huber, C., \& Biedermann, H. (2020). Dynamic criticality assessment as a supporting tool for knowledge retention to increase the efficiency and effectiveness of maintenance. Proceedings of the $1^{\text {st }}$ Conference on Production Systems and Logistics (CPSL), 48-57. https://doi.org/10.15488/9640

[2] Ansari, F. (2019). Knowledge Management 4.0: Theoretical and Practical Considerations in Cyber Physical Production Systems. IFAC-PapersOnLine, 52(13), 1597-1602. https://doi.org/10.1016/j.ifacol.2019.11.428

[3] Biedermann, H. \& Topic, M. (2020). Digitalisierung im Kontext von Nachhaltigkeit und Klimawandel - Chancen und Herausforderungen für produzierende Unternehmen. A. SihnWeber und F. Fischler (Hg.): CSR und Klima-wandel. Berlin, Heidelberg: Springer Berlin Heidelberg (Management-Reihe Corporate Social Responsibility), 41-62. https://doi.org/10.1007/978-3-662-59748-4_4

[4] Passath, T. \& Huber, C. (2020). Asset Management unter der Perspektive der Nachhaltigkeit. WINGbuiness 03/20, Graz, 11 15.

[5] Shafto, M., Conroy, M., Doyle, R., Glaessgen, E., Kemp, C., LeMoigne, J., \& Wang, L. (2010). Modeling, Simulation,
Information Technology and Processing Roadmap. NASA, https://www.nasa.gov/sites/default/files/501321main_TA11ID rev4 NRC-wTASR.pdf

[6] Hirsch-Kreinsen, H., Kubach, U., Stark, R., Wichert, G. von, Hornung, S., Hubrecht, L., et al. (2019). Themenfelder Industrie 4.0. Forschungs- und Entwicklungsbedarfe zur erfolgreichen Umsetzung von Industrie 4.0. https://www.acatech.de/wp-

content/uploads/2019/09/Forschungsbeirat_Themen-felderIndustrie-4.0.pdf (Accessed: 25.08.2020)

[7] Hochhalter, J., Leser, W. P., Newman, J. A., Gupta, V. K., Yamakov, V., Cornell, S. R., et al. (2014). Coupling DamageSensing Particles to the Digitial Twin Concept. NASA/TM2014-218257. https:/nari.arc.nasa.gov/sites/default/files/ Hochhalter_NASA-TM-2014-218257_0.pdf

[8] Grieves, M. (2014). Digital twin: manufacturing excellence through virtual factory replication. White paper, 1, 1-7.

[9] Ansari, F., Nixdorf, S., \& Sihn, W. (2020). Insurability of Cyber Physical Production Systems: How Does Digital Twin Improve Predictability of Failure Risk? IFAC-PapersOnLine, 53(3), 295-300. https://doi.org/10.1016/j.ifacol.2020.11.063

[10] Uhlenkamp, J.-F., Hribernik, K., Wellsandt, S., \& Thoben, K.D. (2019). Digital Twin Applications: A first systemisation of their dimensions. 2019 IEEE International Conference on Engineering, Technology and Innovation (ICE/ITMC). Valbonne Sophia-Antipolis, France, 17.06.2019 - 19.06.2019, 1-8. https://doi.org/10.1109//CE.2019.8792579

[11] Scully, P. \& Lueth, K. L. (2020). Digital Twin Insights Report 2020. Unter Mitarbeit von IoT Analytics.

[12] Kritzinger, W., Karner, M., Traar, G., Henjes, J., \& Sihn, W. (2018). Digital Twin in manufacturing: A categorical literature review and classification. IFAC-PapersOnLine, 51(11), 10161022. https://doi.org/10.1016/j.ifacol.2018.08.474

[13] Tao, F., Zhang, H., Liu, A., \& Nee, A. Y. C. (2019). Digital Twin in Industry: State-of-the-Art. IEEE Trans. Ind. Inf., 15(4), 2405-2415. https://doi.org/10.1109/TII.2018.2873186

[14] Rosen, R., Wichert, G. von, Lo, G., \& Bettenhausen, K. D. (2015). About the Importance of Autonomy and Digital Twins for the Future of Manufacturing. IFAC-PapersOnLine, 48(3), 567-572. https://doi.org/10.1016/j.ifacol.2015.06.141

[15] Dietz, M., Putz, B., \& Pernul, G. (2019). A Distributed Ledger Approach to Digital Twin Secure Data Sharing. Foley, S. N. (Ed.): Data and Applications Security and Privacy XXXIII, Bd. 11559. Cham: Springer International Publishing (Lecture Notes in Computer Science), 281-300. https://doi.org/10.1007/978-3-030-22479-0_15

[16] Gerhard, D., Neges, M., \& Wolf, M. (2020). Übertragung von Konzepten des Digitalen Zwillings auf die Produktion von Betonfertigteilen in der Bauindustrie. ZWF Zeitschrift für wirtschaftlichen Fabrikbetrieb, 115 (special), 58-61. https://doi.org/10.3139/104.112313

[17] Anderl, R., Haag, S., Schützer, K., \& Zancul, E. (2018). Digital twin technology - An approach for Industrie 4.0 vertical and horizontal life-cycle integration. it - Information Technology, 60(3), 125-132. https://doi.org/10.1515/itit-2017-0038

[18] Gerhard, D. (2017): Product life-cycle management challenges of CPPS. Multi-Disciplinary Engineering for Cyber-Physical Production Systems, Springer, 89-110. https://doi.org/10.1007/978-3-319-56345-9_4

[19] Qi, Q. \& Tao, F. (2018). Digital Twin and Big Data towards Smart Manufacturing and Industry 4.0: 360 Degree Comparison. IEEE Access, 6, 3585-3593. https://doi.org/10.1109/ACCESS.2018.2793265

[20] Barthelmey, A., Lee, E., Hana, R., \& Deuse, J. (2019). Dynamic digital twin for predictive maintenance in flexible 
production systems. IECON 2019 - $45^{\text {th }}$ Annual Conference of the IEEE Industrial Electronics Society. Lisbon, Portugal, 14.10.2019 - 17.10.2019, 4209-4214 https://doi.org/10.1109/IECON.2019.8927397

[21] Beierle, C. \& KernIsberner, G. (2014). Methoden wissensbasierter Systeme: Grundlagen, Algorithmen, Anwendungen (Methods of Knowledge-Based Systems: Fundamentals, Algorithms and Applications), Springer

[22] Ansari, F. \& Glawar, R. (2018). Knowledge-Based Maintenance. In Instand-haltungslogistik, Matyas, K. (Ed.), $7^{\text {th }}$ Edition, Carl Hanser Verlag, 12/2018, 318-342

[23] Bärenfänger-Wojciechowski, S., Austerjost, M., \& Henke, M. (2017). Smart Maintenance-Asset Management der Zukunft: Ein integrativer Management-Ansatz (Smart Maintenance Asset Management for the Future: An Integrative Management Approach), 102-106. http://publica.fraun-hofer.de/dokumente/ N-461811.html (Accessed: 16.07.2020)

[24] Glawar, R., Kemeny, Z., Nemeth, T., Matyas, K., Monostori, L., \& Sihn, W. (2016). A Holistic Approach for Quality Oriented Maintenance Planning Supported by Data Mining Methods. Procedia CIRP, 57, 259-264. https://doi.org/10.1016/j.procir.2016.11.045

[25] Tinga, T., Wubben, F., Tiddens, W., Wortmann, H., \& Gaalman, G. (2020). Dynamic maintenance based on functional usage profiles. JQME ahead-of-print, p. 1. https://doi.org/10.1108/JQME-01-2019-0002

[26] Ansari, F. (2020). Costbased text understanding to improve maintenance knowledge intelligence in manufacturing enterprises. Computers \& Industrial Engineering, 141, p. 106319. https://doi.org/10.1016/j.cie.2020.106319

[27] Dienst, S., Ansari, F., \& Fathi, M. (2015). Integrated system for analysing maintenance records in product improvement. Int $J$ Adv Manuf Technol, 76(1-4), 545-564. https://doi.org/10.1007/s00170-014-6228-2

[28] Li, C., Mahadevan, S., Ling, Y., Choze, S., \& Wang, L. (2017). Dynamic Bayesian Network for Aircraft Wing Health Monitoring Digital Twin. AIAA Journal, 55(3), 930-941. https://doi.org/10.2514/1.J055201

[29] Ansari, F., Glawar, R., \& Sihn, W. (2020). Prescriptive Maintenance of CPPS by Integrating Multimodal Data with Dynamic Bayesian Networks. Beyerer, J., Maier, A., \& Niggemann, O. (Ed.): Machine Learning for Cyber Physical Systems, Bd. 11. Berlin, Heidelberg: Springer Berlin Heidelberg (Technologien für die intelligente Automation), 18. https://doi.org/10.1007/978-3-662-59084-3_1

[30] Li, S., Wu, Y., Xu, Y., Hu, J., \& Hu, J. (2018). A Bayesian Network Based Adaptability Design of Product Structures for Function Evolution. Applied Sciences, 8(4), 493. https://doi.org/10.3390/app8040493

[31] Aydin, R. \& Badurdeen, F. (2019). Sustainable product line design considering a multilifecycle approach. Resources, Conservation and Recycling, 149, 727-737. https://doi.org/10.1016/j.resconrec.2019.06.014

[32] Al-Radhi, M. \& Heuer, J. (1995). Total productive maintenance. Konzept, Umsetzung, Erfahrung. München, Wien: Carl Hanser Verlag.

[33] Passath, T. \& Huber, C. (2019). Dynamische Instandhaltungsstrategieanpassung durch Anlagenkritikalitätsbewertung. BHM Berg- und Hüttenmännische Monatshefte, 164(1), 7-12. https://doi.org/10.1007/s00501-018-0812-y

[34] Kinz, A. \& Passath, T. (2018). Ressourceneffiziente Anlagenbewirtschaftung. WING-business. Jg., 1, 29-32. https://doi.org/10.24989/medienjournal.v29i2.332
[35] Crespo Marquez, A., León, P., Gomez Fernandez, J. F., Parra, C., \& López-Campos, M. (2009). The maintenance management framework. JQME, 15, 167-178. https://doi.org/10.1108/13552510910961110

[36] Kinz, A. \& Biedermann, H. (2015). Anlagenspezifische Instandhaltungsstrategiewahl durch strukturierte Anlagenbewertung. Biedermann, H. (Ed.): Smart Maintenance, Köln: TÜV Media, 221-238.

[37] Gupta, S., Bhattacharya, J., Barabady, J., \& Kumar, U. (2013). Costeffective importance measure: A new approach for resource prioritisation in a production plant. International Journal of Quality \&amp Reliability Management, 30, 379386. https://doi.org/10.1108/02656711311308376

[38] Gopalakrishnan, M., Skoogh, A., Salonen, A., \& Asp, M. (2019). Machine criticality assessment for productivity improvement. Int J Productivity \& Perf Mgmt, 68(5), 858-878. https://doi.org/10.1108/IJPPM-03-2018-0091

[39] Kinz, A., Schröder, W., Passath, T., Praher, P., \& Freudenthaler, B. (2017). Optimierung des anlagenspezifischen Instandhaltungsstrategiemixes am Beispiel eines komplexes Fertigungssystems. Köln: TÜV Media GmbH (Biedermann, H. (Ed.): Erfolg durch Lean Smart Maintenance: Bausteine und Wege des Wandels: 31 Instandhaltungsforum).

[40] Passath, T. \& Kinz, A. (2018). Einführung eines strategischen Asset Management Systems am Beispiel der Zellstoffindustrie. Predicitve Maintenance-Realität und Vision: 32. Instandhaltungsforum. TÜV Media GmbH Rheinland Group. 41-64.

[41] Passath, T., Hochstrasser, P., Kühnast-Benedikt, R., \& Simbeni, L. (2020). Anlagenspezifisches Risikomanagement in der gelebten Praxis - Kritikalität, Wissenssicherung und Transparenzsteigerung. Köln: TÜV Media GmbH (Biedermann, H. (Ed.): Wertschöpfende Instandhaltung: Tools, Methoden und Modelle: 34. Instandhaltungsforum), 189-220.

[42] Passath, T. \& Mertens, K. (2019). Decision Making in Lean Smart Maintenance: Criticality Analysis as a Support Tool. IFAC-PapersOnLine, 52(10), 364-369. https://doi.org/10.1016/j.ifacol.2019.10.058

[43] Adams, J., Srinivasan, R., Parlikad, A. K., González-Prida, V., \& Crespo, A. M. (2016). Towards Dynamic Criticality-Based Maintenance Strategy for Industrial Assets. IFACPapersOnLine, 49(28), p. 103-107. https://doi.org/10.1016/j.ifacol.2016.11.018

[44] Bharadwaj, U. R., Silberschmidt, V. V., \& Wintle, J. B. (2012). A risk based approach to asset integrity management. JQME, 18(4), 417-431. https://doi.org/10.1108/13552511211281570

[45] Braglia, M., Frosolini, M., \& Montanari, R. (2003). Fuzzy criticality assessment model for failure modes and effects analysis. Int J Qual \& Reliability Mgmt, 20(4), 503-524. https://doi.org/10.1108/02656710310468687

[46] Petersdorff, H. von, \& Vlok, P. J. (2014). Priortising Maintenance Improvement Opportunities in Physical Asset Management. SAJIE, 25(3). https://doi.org/10.7166/25-3-755

[47] Eldawlatly, S., Zhou, Y., Jin, R., \& Oweiss, K. G. (2010). On the use of dynamic Bayesian networks in reconstructing functional neuronal networks from spike train ensembles. Neural computation, 22(1), 158-189. https://doi.org/10.1162/neco.2009.11-08-900

[48] Schenkelberg, K., Seidenberg, U., \& Ansari, F. (2020). Analysing the impact of maintenance on profitability using dynamic bayesian networks. Procedia CIRP, 88, 42-47. https://doi.org/10.1016/j.procir.2020.05.008 
[49] Constantinou, A. C., Fenton, N., Marsh, W., \& Radlinski, L. (2016). From complex questionnaire and interviewing data to intelligent Bayesian network models for medical decision support. Artificial intelligence in medicine, 67, 75-93. https://doi.org/10.1016/j.artmed.2016.01.002

[50] Cózar, J., Puerta, J. M., \& Gámez, J. A. (2017). An Application of Dynamic Bayesian Networks to Condition Monitoring and Fault Prediction in a Sensored System: a Case Study. IJCIS, 10(1), p. 176. https://doi.org/10.2991/ijcis.2017.10.1.13

[51] DIN EN 50126-1:2018-10; VDE 0015-103-1:2018-10. Bahnanwendungen - Spezifikation und Nachweis von Zuverlässigkeit, Verfügbarkeit, Instandhaltbarkeit und Sicherheit (RAMS), Teil 1: Generischer RAMS Prozess.

\section{Authors' contacts:}

Theresa Passath, Dipl.-Ing.

Montanuniversitaet Leoben, Department of Economic- and Business Management, Franz Josef Straße 18, 8700 Leoben, Austria

+43 3842402 6013, theresa.passath@unileoben.ac.at

Cornelia Huber, Mag.

Montanuniversitaet Leoben, Department of Economic- and Business Management, Franz Josef Straße 18, 8700 Leoben, Austria

+433842 402 6006, cornelia.huber@unileoben.ac.at

Linus Kohl, Dipl.-Ing.

TU Wien, Research Group of Smart and Knowledge-Based Maintenance,

Theresianumgasse 27, 1040 Vienna, Austria

+4315880133048, linus.kohl@tuwien.ac.at

Hubert Biedermann, o. Univ.-Prof. Dipl.-Ing. Dr. mont

(Corresponding author)

Montanuniversitaet Leoben, Department of Economic- and Business Management,

Franz Josef Straße 18, 8700 Leoben, Austria

+4338424026000, hubert.biedermann@unileoben.ac.at

Fazel Ansari, Dr.-Ing.

TU Wien, Research Group of Smart and Knowledge-Based Maintenance,

Theresianumgasse 27, 1040 Vienna, Austria

+4315880133048, fazal.ansari@tuwien.ac.at 